\title{
Heat Emergencies: Perceptions and Practices of Community Members and Emergency Department Healthcare Providers in Karachi, Pakistan: A Qualitative Study
}

\author{
Uzma Rahim Khan ${ }^{1}$, Naveed Ahmed ${ }^{1}$ D, Rubaba Naeem ${ }^{1}$, Umerdad Khudadad ${ }^{1}{ }^{(D,}$ Sarwat Masud ${ }^{1}$, \\ Nadeem Ullah Khan ${ }^{1}$ and Junaid Abdul Razzak ${ }^{2,3, *(D)}$
}

1 Department of Emergency Medicine, Aga Khan University, Karachi 74800, Pakistan; uzma.khan@aku.edu (U.R.K.); naveed.ahmad@aku.edu (N.A.); rubabakhan25@gmail.com (R.N.); umerhaideri47@gmail.com (U.K.); sarwat.masud@scholar.aku.edu (S.M.);

nadeemullah.khan@aku.edu (N.U.K.)

2 Centre for Global Emergency Care, Department of Emergency Medicine, Johns Hopkins University School of Medicine, Baltimore, MD 21218, USA

3 Centre of Excellence for Trauma and Emergencies, Aga Khan University, Karachi 74800, Pakistan

* Correspondence: junaid.razzak@jhu.edu

check for updates

Citation: Khan, U.R.; Ahmed, N.; Naeem, R.; Khudadad, U.; Masud, S.; Khan, N.U.; Razzak, J.A. Heat Emergencies: Perceptions and Practices of Community Members and Emergency Department Healthcare Providers in Karachi, Pakistan: A Qualitative Study. Int. J. Environ. Res. Public Health 2021, 18, 4736. https://doi.org/10.3390/ ijerph18094736

Academic Editors: Elisabeth Dorant and Chuansi Gao

Received: 4 March 2021

Accepted: 22 April 2021

Published: 29 April 2021

Publisher's Note: MDPI stays neutral with regard to jurisdictional claims in published maps and institutional affiliations.

Copyright: (c) 2021 by the authors. Licensee MDPI, Basel, Switzerland. This article is an open access article distributed under the terms and conditions of the Creative Commons Attribution (CC BY) license (https:// creativecommons.org/licenses/by/ $4.0 /)$.

\begin{abstract}
Heat waves are the second leading cause of weather-related morbidity and mortality affecting millions of individuals globally, every year. The aim of this study was to understand the perceptions and practices of community residents and healthcare professionals with respect to identification and treatment of heat emergencies. A qualitative study was conducted using focus group discussions and in-depth interviews, with the residents of an urban squatter settlement, community health workers, and physicians and nurses working in the emergency departments of three local hospitals in Karachi. Data was analyzed using content analysis. The themes that emerged were (1) perceptions of the community on heat emergencies; (2) recognition and early treatment at home; (3) access and quality of care in the hospital; (4) recognition and treatment at the health facility; (5) facility level plan; (6) training. Community members were able to recognize dehydration as a heat emergency. Males, elderly, and school-going children were considered at high risk for heat emergencies. The timely treatment of heat emergencies was widely linked with availability of financial resources. Limited availability of water, electricity, and open public spaces were identified as risk factors for heat emergencies. Home based remedies were reported as the preferred practice for treatment by community members. Both community members and healthcare professionals were cognizant of recognizing heat related emergencies.
\end{abstract}

Keywords: heat emergencies; heat exposure; extreme heat events; perceptions; Pakistan

\section{Introduction}

Heat emergencies are a public health problem of significance. Global climate change has been related to rising temperatures, which have resulted in heatwaves, more severe droughts, heavy rains, and intense hurricanes in various parts of the world [1,2]. These heat related emergencies have affected communities that were unprepared to handle them. Extreme air temperature contributes directly to cardiovascular and respiratory disease deaths, especially among the elderly. More than 166,000 people died as a result of heatwaves between 1998 and 2017, including more than 70,000 in Europe during the 2003 heatwave. Between 2000 and 2016, the number of people exposed to heatwaves went up by nearly 125 million.

The UNHCR's report on weather-related incidents from 1995 to 2015 highlighted the importance of risk identification and reduction in vulnerable countries. [3]. With regard to heat events, Chicago, United States reported 514 deaths in July 1995 [4] followed by California that recorded a higher number of emergency visits in 2006 [5]. Similar burden of 
heat emergencies has been observed in Western Europe including France, Germany and Spain [6,7]. In addition, New South Wales reported a $13 \%$ rise in all-cause mortality, and a $14 \%$ increase in ambulance calls related to heat emergencies in 2011 [8]. Furthermore, India reported 1000 excessive deaths in Ahmedabad as a result of extreme heat in 2010 [9].

Pakistan ranks 7 th on the list of the top 10 countries with the climate risk index score of 30.5 and a total number of 141 weather-related events in the past 10 years [10]. Karachi, being located in a hot climate area is at risk for heat related emergencies, due to the high concentration of infrastructure and limited greenery [11]. Temperatures soar to an extreme of $45^{\circ} \mathrm{C}$ during the months of May to July, along with high humidity of $30-95 \%$ as a daily average from 2006 to 2015 [12]. The 30-year average maximum temperature for June, the hottest summer month in Karachi, is $34.8^{\circ} \mathrm{C}$ [13]. There was a "heat spell" in Karachi in June 2015, causing a state of emergency in the city, claiming more than 1200 lives in a span of four days [14].

Heat emergencies include dehydration, heat cramps, heat exhaustion, heat stroke, and death [15]. Quantitative literature about the epidemiology of heat emergencies has identified that the elderly, children, outdoor workers, and people with comorbidities are at greater risk for heat emergencies [1]. The approach used by most of the epidemiologists to measure heat illnesses has been quantitative [16,17]. Some researchers have identified the need for analyzing the vulnerability of at-risk populations through a qualitative approach One such study from Sweden explored communities' perceptions regarding city heat and identified social isolation and female gender as risk factors for heat emergencies in addition to other known risks [16]. A similar study from Australia identified that negative perceptions about heat disasters among the elderly increased their risk for heat illness and hospitalization [18]. Some qualitative studies have explored the perceptions of outdoor workers towards occupational heat injuries, but little is known about the perceptions of healthcare providers and vulnerable communities towards heat emergencies [15,19-24].

It is hypothesized that a lack of water supply, long and unpredictable power outages, and a lack of awareness among communities and residents contributed to the high number of heat-related deaths in Karachi in 2015, but evidence is lacking [12]. To better understand the threats that heat-related emergencies pose to Karachi's populations, the perceptions of local community members and healthcare workers must be explored, the findings of which can be used to develop heat-related emergency prevention strategies [25]. Therefore, the aim of this study was to understand the perceptions and practices of healthcare providers, along with community members regarding diagnosing and treating heat emergencies in Karachi.

\section{Materials and Methods}

\subsection{Study Design}

The study was conducted in November 2017, in Karachi, Pakistan, as part of the Heat Emergency Awareness and Treatment (HEAT) trial (NCT03513315). The HEAT trial was carried out in the months of summer. However, this qualitative study was embedded in the HEAT trial and conducted in November considering that heatwave is a tropical phenomenon in Pakistan. In Karachi, the temperature in the month of November remains moderate ranging from 20 to $32{ }^{\circ} \mathrm{C}$. In addition, we think that the perception about heat is independent of weather conditions. One of the objectives in the heat trial was to develop a community heat prevention guideline. To facilitate the contextual development of the guideline catering to the needs of community and emergency healthcare workers, a qualitative study was conducted using focus group conversations (FGDs) and in-depth individual interviews (IDIs). The participants were community members, community healthcare workers, and Emergency Department healthcare workers. The study settings were rural areas of Karachi; Ibrahim Hyderi where the cluster randomized trial was conducted, and three hospitals, which were considered as the catchment population of the area. 


\subsection{Study Population and Setting}

Focus group discussions were conducted with the residents of Ibrahim Hyderi (local vicinity in Karachi), including community healthcare workers. The sample pool of FGDs comprised a wide range of participants to ensure variability in the responses. They were approached through a health organization working in the area which is trusted by the community. This health organization was part of the Heat Trial. The FGDs were conducted at the office of the health organization. The discussion spanned around $45 \mathrm{~min}$.

In-depth interviews were conducted with emergency care workers of three major hospitals in Karachi. All the interviews were conducted at the participant's hospital, at a convenient place and time. The average duration of the interviews was $30 \mathrm{~min}$.

\subsection{Data Collection and Analysis}

The FGDs and IDIs were conducted until saturation was achieved [26]. The research team trained in qualitative research, moderated the FGDs and IDIs. The research team and participants were unknown to each other to establish a common epistemological ground for the interviews [27]. The FGDs and IDIs were conducted by the two members of the research team (NA \& RN). A semi structured IDI and FGD guide was prepared by the research team, which was reviewed by a qualitative research expert and a heat emergencies expert. (Appendices A and B). All IDIs and FGDs were conducted in the local language, Urdu, and were audio-recorded, after obtaining written consent from all the participants. Each participant was assigned a unique code. Confidentiality was maintained using these unique codes during transcription of the audio interviews. This allowed the researchers to anonymize the interviews while identifying valuable information like demographics, themes, and subcategories.

The interviews were transcribed by two authors (NA and RN). These authors further used content analysis approach [28] to identify the emerging themes and subthemes from the transcripts (Figure 1). Consensus was then reached between the two authors and a thematic dictionary was created, with definitions for each theme and quotes to support it. Rigor and trustworthiness in the study was established through following Lincoln and Guba's criteria [29]. The study's credibility was enhanced by emphasizing the purpose to learn from respondents through open and nonjudgmental attitude of interviewer during FGDs and IDIs.

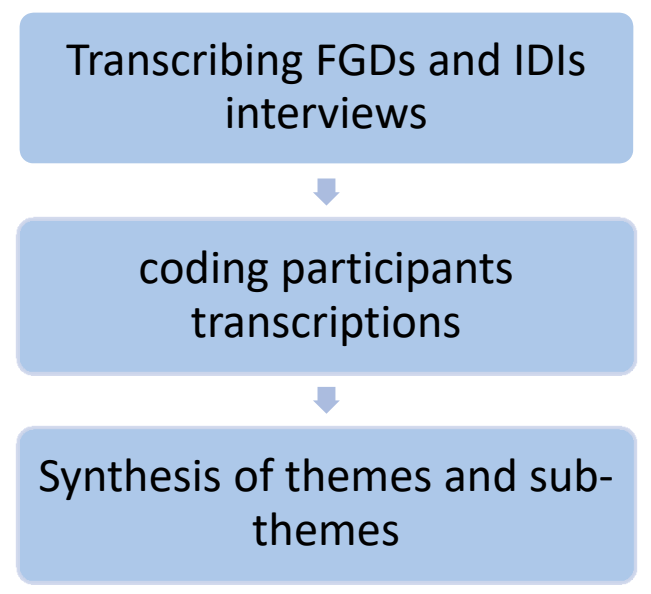

Figure 1. Qualitative data analysis sequence.

Approval to conduct the study was obtained from the Ethics Review Committee of the Aga Khan University, Karachi, Pakistan.

\section{Results}

A total of 30 people participated in the FGDs (Table 1). The mean age of the sample was 34 years. The women were housewives and community healthcare workers whereas 
half the men were fishermen, and the rest were a tailor, students, and office workers. Among the participants, $60 \%$ had intermediate level education.

Table 1. Demographic characteristics of the participants from FGDs.

\begin{tabular}{cc}
\hline Characteristics & Total $(\boldsymbol{n}=\mathbf{3 0})$ \\
\hline Age (mean, years) & 34 \\
Gender & $12(40 \%)$ \\
Male & $18(60 \%)$ \\
Female & \\
Occupation & $10(33.3 \%)$ \\
Housewife & $5(16.6 \%)$ \\
Fisherman & $1(3.3 \%)$ \\
Tailor & $10(33.3 \%)$ \\
Community health workers & $2(6.6 \%)$ \\
Office work & $2(6.6 \%)$ \\
Student & $5(16 \%)$ \\
Formal education & $18(60 \%)$ \\
Grade 10 and below & $1(3 \%)$ \\
10-12 grades & \\
$>12$ years &
\end{tabular}

\subsection{Themes Emerging from FGDs with Community Residents}

Respondents discussed the challenges that the community face during periods of extreme heat in Karachi. In-depth narratives revealed the preventive and treatment mechanisms used by community to deal with heat emergencies. Two themes were drawn from the narratives depicting recognition and treatment of heat emergencies in the community and access to and quality of care in the hospitals in terms of heat crises.

\subsubsection{Recognition and Early Treatment of Heat Emergencies at Home}

Participants from all the three FGDs admitted that early recognition of symptoms is important in managing patients with heat emergencies. One of the challenges in treating heat-related cases at home is that it is not recognized in the early stages of heat emergencies, which prevents the implementation of appropriate care. They expressed that cases are not recognized at the earlier stages of the condition, which is the biggest barrier in the treatment. Initially, the cases are treated for raised body temperature with acetaminophen, home remedies, and sprinkling water over the head and eyes if the patient has lost consciousness. The majority mentioned lack of financial resources as the cause of over reliance on home remedies, while others stated that people lacked the ability to recognize heat-induced conditions. A CHW from community informed,

"People in the community keep treating patients at home at the initial stages, the decision to go to the hospital is taken in extreme conditions. Sometimes they call us, and we help them but most of the time treatment takes place at home with home remedies." (FGD \# 3)

Almost all the participants in the FGDs stated that drinking plenty of water during hot weather could help prevent heat emergencies. Moreover, the community residents informed that drinking lemonade and other homemade drinks, such as "lassi" (a mixture made of yogurt, milk, and water) helps hydrating the body. However, they emphasized that only simple water is enough to rehydrate if it is available. A male member of the community narrated,

"Drinking lemonade has good effects on the body on hot summer days, I drink a lot whenever I am feeling low" (FGD \# 1)

Similarly, a mother from the community verbalized,

"I often make lemonade for my kids once they are back home from school, particularly, when I feel that weather is hot outside and my kids might have been affected by the weather" (FGD \#2) 
Community residents, both males and females perceived that drinking water or taking a shower soon after entering home in hot weather can cause paralysis of body or other infectious diseases and thought that this practice needed to be avoided. A male member from community verbalized,

"I always advise my kids to avoid the practice of drinking cold water immediately after entering home in hot weather; take rest for a few minutes to allow the body to cool down.

Drinking water immediately could cause other diseases, therefore, drink water once your body temperature comes to normal" (FGD \# 1)

Modification in lifestyle can play a pivotal role in preventing heat emergencies such as drinking plenty of water and reducing strenuous activities. Participants narrated that eating less spicy foods and wearing light colored clothes help the body in maintaining its homeostasis. The male members thought that wearing a cap when going out in the sun and drinking water frequently during work can help a person stay safe from the harmful effects of heat. On the other hand, the community health workers (CHWs) believed that the community residents are not always aware of these preventive measures, which results in incidence of dehydration and heat emergencies. Both, the male community residents and CHWs felt that the structure of the houses in the community also contributed to heat emergencies, as the element of ventilation is rarely considered during construction. One male member from community expressed,

"The design of the house is rarely considered during construction of the house, even the rooms within the house are not well ventilated" (FGD \# 1)

Heat emergencies in the community can be considerably prevented by ensuring the adequate supply of water and electricity. In summers, the minimal availability of both largely affects health of community dwellers. Frequent power outrages for hours and sometimes for a stretch of days affect supply of water and, because of which, the community residents must drink stored and unhygienic water. A female from community narrated that,

"We face a lot of issues with the supply of water in summers, unavailability of electricity hampers water supply. We bring water from our neighborhoods and store" (FGD \#2 group)

\subsubsection{Access and Quality of Care in the Hospital}

The number of healthcare facilities available in the community is inadequate with limited health services only targeting specific diseases. One male member of community stated that lack of transport facilities to transfer patients to healthcare facilities posed an added financial burden on the families. Therefore, often the decision regarding seeking healthcare depends on the financial resources, and medical care is accessed only in extreme situations.

"We have to hire a private car to transfer our patients to a larger healthcare facility. We take this decision in cases when the patient is critically ill or about to die and when all the home remedies have been tried on the patient [ ... ] because we can't afford private transport" (FGD \# 1)

Moreover, the participants expressed concerns regarding lack of trust in emergency medical services. They stated that poor quality of services, harsh behavior of the healthcare professionals and the complex process of getting care at public sector hospitals made it difficult to avail healthcare services. They, therefore preferred home remedies or seeking healthcare from nearby private healthcare facilities, despite financial hardship. One participant said,

"I have a very bad experience of going to a doctor because of number of reasons, one of them is their harsh behavior." (FGD \#3)

Cultural constraints are another contributing factor for not seeking healthcare, particularly among women because they are not allowed to go alone without a male chaperone. As one female verbalized, 
"We have to wait till evening for our males to arrive home and accompany us to a doctor and often the nearby clinics are closed by then" (FGD \#2)

\subsection{Themes Emerging from IDIs of Healthcare Professionals}

The participants in the IDIs were doctors and nurses ranging from 25 to 50 years of age and all of them were involved in the management of patients during the heat wave emergency of 2015 (Table 2). Three themes emerged from the interviews with the healthcare professionals. However, both healthcare professionals and community members emphasized the importance of the early recognition and treatment of heat emergencies.

Table 2. Demographic characteristics of the IDI participants.

\begin{tabular}{cc}
\hline Characteristics & Total $(\boldsymbol{n = 6 )}$ \\
\hline Age (mean, years) & 38 \\
Male & $3(50 \%)$ \\
Female & $3(50 \%)$ \\
Profession & \\
Doctor & $3(50 \%)$ \\
Nurse & $3(50 \%)$ \\
Work experience (range, years) & 5 to 25 \\
Experience of 2015 heat wave & $6(100 \%)$ \\
\hline
\end{tabular}

\subsubsection{Recognition and Treatment of Heat Emergencies}

Generally, the healthcare providers felt confident of their ability to recognize heat illnesses. They thought that they were more aware of signs and symptoms of heat illnesses since the heat wave of 2015. When patients visit an emergency department with dehydration, dizziness and rapid pulse; healthcare providers recognize that this is heat illness and provide treatment to them accordingly. A male doctor from a public health facility stated,

"So sometimes in extreme heat when the temperature rises up to 40 degrees, patients present with dehydration. They often visit with complaints about altered level of consciousness and shivering or chills as well. So, in this scenario we hydrate them for their survival." (IDI 01-DP20N-M)

The respondents further explained other signs and symptoms that patients affected by heatwaves, such as lethargy, low blood pressure, rapid heart-beat, and high body core temperature. A male nurse from a public health facility stated,

"Patients are lethargic, they have low blood pressure, and if they have had more sun exposure, they come with high temperature as well" (IDI 02-NP7Y-M)

Regarding treatment of patients with heat emergencies, healthcare providers bring down the patient's temperature by sponging, icing, and keeping them in air-conditioned room. Further, they follow the workup for heat affected patients as soon as the patient is identified as having a heat stroke. Two participants expressed this as follows,

"To manage heat stroke patients, we mainly do sponging. We have a tub and pipe for them to take showers, we do icing, we keep them in an airconditioned area and lastly we give 5\% Dextrose, if not controlled." (IDI 06-DDY-M)

"Patients often do complain of severe headache as soon as they reach to hospital. We immediately take them inside and sponge their heads, we check their temperature, secure IV line, and hydrate them." (IDI 04-ND28Y-F)

\subsubsection{Facility Level Plan}

Based on their experience, the participants stated that dealing with heat emergencies required facility level planning and physical resources. They mentioned that essential supplies are needed to handle heat emergencies as per the plan. They also emphasized the need for a proper management plan to address the burden of heat emergencies; plans 
were being followed to some extent in each facility. A respondent from a public health facility stated,

"We need ample fluids because dehydration is common in heat strokes. We should be prepared to have all the items that should be in the crash cart such as IV cannula, oxygen masks, medicines and intubation for more sick patients." (IDI 02-NP7Y-M)

The participants further highlighted the need for a multidisciplinary team to manage heat-stroke. A doctor and a nurse from the public health facilities expressed their views as follows,

"This should be teamwork, not only work of the emergency department. We have to involve other specialties such as medicine department, nephrology department, cardiology etc. [ ... ] Sometimes patients become very sick, and this leads to sepsis. So, in this situation an infectious disease specialist should be contacted to deal with such patients. So, teamwork is essential, without teamwork it is not possible." (IDI 01-DP20N-M)

"The first priority is that there should be air-conditioned areas so that patients get cooled directly as they enter the hospital, and their temperature stays on low. Simultaneously, fluids should be provided to them to balance their electrolytes" (IDI 03-ND28-H-F)

A doctor from the public hospital mentioned the physical resources required for heat stroke patients, such as proper ICU, ward, and ambulance for timely transportation. She further explained that a standard set of requirements is the same for routine patient and patients affected with heat-stroke. A female doctor from a public health facility mentioned,

"Proper ICU is required, proper ward care is required, an ambulance to shift patients is required, so we need everything that a normal routine patient need" (IDI 05-DD29-Y-F)

\subsubsection{Training}

Most of the participants emphasized that there should be regular trainings on the management of heat emergencies. The training should cover all the components, from basic to complex case scenarios, on disease recognition, diagnosis, and management. In addition, they emphasized on the availability of guidelines for uniformity in practices. They stated that guidelines will improve the clinical decision making of the healthcare providers. As two of the participants said,

"There should be regular trainings and reinforcement on the implementation of guidelines to bring uniformity in practice." (IDI 03-ND28-H-F)

"There should be theoretical and practical training so that one is aware that summer is coming, and what should be the criteria to deal with heat stroke patients." (IDI 01-DP20N-M)

\section{Discussion}

A qualitative approach was used in this study to investigate the perceptions and practices of a local Karachi community and its healthcare providers regarding recognizing and managing heat emergencies. Both the community and healthcare providers were aware of heat emergencies, especially after the 2015 Karachi heat wave. The discussion with community members revealed that the socioeconomic status of households can have a significant impact on the treatment of heat illnesses. The private sector of the healthcare system in Pakistan delivers $70 \%$ of the total healthcare services which is based on fee for services [30]. There is also a huge disparity in accessing healthcare services with $30 \%$ of the population living with absolute poverty. In addition, the healthcare expenditure as percentage of the gross domestic product is only 3.2\% in Pakistan [31]. Similar findings have previously been observed; individuals from low socioeconomic status had poorer health outcomes and higher mortality because they lived in small, overcrowded housing with limited access to water, cooling appliances, and health facilities, as seen in Karachi's 2015 heat wave [32-34]. Emergency care workers identified an increased burden on 
the emergency department as a result of heat illnesses in a city that already has a high prevalence of endemic illnesses [35].

Outdoor laborers were found to be more vulnerable to heat emergencies. These results are consistent with a study from Ahmedabad, India, which listed outdoor workers as a vulnerable group for heat illnesses [36]. Previous studies have identified workers in humid indoor/outdoor conditions [14] and women working in kitchens as vulnerable groups, which were not identified in our study. Heat emergencies have previously been identified as largely preventable through the provision of necessities such as water and electricity, as well as educating about the health risks of heat $[15,21,22]$. Furthermore, drinking traditional yoghurt, which is commonly used in South Asia provides the body with the liquid and nutrients in an easily digestible form, which are lost while sweating as an effect of exposure to heatwave. [37].

Members of the community identified financial and structural barriers to accessing emergency care for heat illnesses. In Pakistan, financial constraints are a common and consistent barrier to accessing healthcare during any illness, including heat emergencies [38]. Furthermore, cultural barriers, such as the belief that a woman visiting a healthcare facility without being accompanied by a male member is unacceptable, hinder timely treatment for heat-related illnesses, despite the fact that women are more vulnerable to heat emergencies while performing domestic chores. Cultural barriers are one of the many reasons for low utilization of healthcare services in many low- and middle-income countries (LMICs) [39]. Poor quality of emergency care services was perceived to be an impeding factor by the communities in obtaining healthcare for heat-related illnesses. Poor quality of care is one of many factors contributing to the underutilization of public healthcare facilities in LMICs [40].

Emergency department personnel had little knowledge of the signs and symptoms of heat illnesses, such as describing shivering as one of the symptoms, which is not indicative of heat illnesses, and mentioning the use of Dextrose 5\% fluid as a treatment, which is not a standard of care [41]. In addition, differentiating between body core, skin, and air temperatures is critical for accurate diagnosis of heat emergencies. In Karachi, there is no uniform method for measuring body core temperatures in hospitals. However, measuring body core temperature and obtaining a history of heat exposure where possible are important for diagnosing heat-related illnesses, especially heat stroke, in the emergency department [42]. In the context of growing local diseases and outbreaks, matching the symptoms with heat was deemed challenging. Our results are consistent with a study conducted in Germany, in which general practitioners (GPs) were unable to identify environmental conditions as possible risk factors for heat emergencies [43].

The healthcare professionals expressed the need for a facility level response plan to deal with heat emergencies effectively. The heatwave in 2015, in Karachi, led to the development of the first heatwave management plan, in consultation with national and international experts [12]. This plan set out strategies for relevant agencies to ensure timely information on weather conditions, interagency coordination, and a public triggered activation system. In addition, strengthening primary healthcare services, to make them more responsive towards the management of the heat-related illnesses, can reduce the burden of heat emergencies in communities. Although ineffective primary care was not identified directly by our community, previous literature shows that the primary healthcare system serves as an early treatment hub for patients [44]. However, this is lacking in Pakistan [45]. Primary healthcare services may improve the health outcomes of the patients by detecting diseases in their early stages, and it can be one of the core elements in the implementation of an extreme heat disaster management plan [46].

\section{Limitations and Strength of the Study}

This study had several limitations. Despite the small sample size, the potential themes emerged by grouping the responses of the participants and saturation in the responses was achieved. The practices reported by the emergency healthcare workers might have been 
influenced by the temptation to offer desirable responses believing their activities were being scrutinized. Moreover, the findings of the study are not intended to be generalizable beyond the scope of the study. Despite these limitations, the study provided contextual knowledge to facilitate the construction of heat prevention and treatment guidelines for communities and healthcare professionals. The study explored the perceptions of the community and healthcare workers simultaneously, which is a strength of this study. The findings from this study can be applicable to other resource constrained settings similar to Karachi. The heterogeneity in the sample pool was ensured by recruiting a wide range of male and female respondents including community dwellers, nurses, physicians and administrative workers who were knowledgeable about and had experience of a phenomenon of interest [47]. Perspectives of policy makers and representatives of the implementation agencies could be another interesting aspect to include in future research.

\section{Conclusions}

This qualitative study has provided new insights into the context of communities and healthcare professionals facing consequences of heat exposure in Karachi. Study findings suggest that there is an awareness about heat emergencies among community members in Karachi. The community perceived dehydration as a heat emergency and managed it with home remedies, cooling, and hydration. Furthermore, heat emergencies were identified to be connected with a shortage of electricity and water supply. The healthcare workers had limited awareness about the signs and symptoms of heat emergencies and perceived the early recognition and treatment of heat emergencies as challenging, in the face of endemic infections having similar presentation. Furthermore, poor quality of public healthcare services, inadequate training, and ineffective implementation of heat wave preparedness plans were identified as impeding factors in the treatment heat emergencies. Considering these aspects, there is a need to carry out preventive actions that take into account the socioeconomic challenges of the communities. This may inform heat prevention policies in communities facing longer and more intense hot spells.

Author Contributions: Conceptualization, J.A.R., N.U.K. and U.R.K.; methodology, U.R.K., N.A. and R.N.; formal analysis, N.A. and R.N.; writing—original draft preparation, N.A., R.N., U.K., U.R.K., S.M.; writing-review and editing, N.U.K., J.A.R., U.R.K., U.K. and S.M.; supervision, U.R.K. and N.U.K.; funding acquisition, J.A.R. and N.U.K. All authors have read and agreed to the published version of the manuscript.

Funding: This research project was funded by Elrha's Research for Health in Humanitarian Crises (R2HC) Programme, which aims to improve health outcomes by strengthening the evidence base for public health interventions in humanitarian crises. R2HC is supported by the UK Foreign, Commonwealth and Development Office (FCDO), Wellcome, and the UK National Institute for Health Research (NIHR).

Institutional Review Board Statement: The study was conducted according to the guidelines of the Declaration of Helsinki and approved by the Ethical Review Committee of the AGA KHAN UNIVERSITY (Reference number 4176-EM-ERC-16, approved on 27 October 2017).

Informed Consent Statement: Informed consent was obtained from all subjects involved in the study.

Data Availability Statement: The data presented in this study are available on request from the corresponding author.

Acknowledgments: The authors would like to acknowledge the administrative support provided by Aman Foundation.

Conflicts of Interest: The authors declare no conflict of interest.

\section{Appendix A}

Guide for Focus Group Discussion

1. What is your overall understanding of extreme heat? 
2. What do people think is the effect of extreme heat on health, if any?

3. How is extreme heat harmful to health?

4. How are people suffering from the effect of extreme heat identified in your area?

5. How are patients with health problems due to extreme heat managed at home? How is the decision made to seek medical care?

6. How is medical care accessed?

7. What are the key challenges in managing people suffering from health problems due to extreme heat at home?

\section{Appendix B}

\section{Guide for IDI with Key Informants}

1. Do you think extreme heat causes health impacts and how?

2. In your opinion, how would you make the diagnosis of the patients with heat emergencies?

3. Do you feel you are able to manage patients with diseases due to extreme heat exposure in your emergency department? Why? Why not?

4. What would you like to see to improve care of these patients?

5. If training was to be given to physicians and nurses, what kind of training should it be?

6. What supplies and equipment are critical to caring for these patients which will help you improve patient outcomes?

\section{References}

1. Luber, G.; McGeehin, M. Climate Change and Extreme Heat Events. Am. J. Prev. Med. 2008, 35, 429-435. [CrossRef]

2. Watts, N.; Adger, W.N.; Agnolucci, P.; Blackstock, J.; Byass, P.; Cai, W.; Chaytor, S.; Colbourn, T.; Collins, M.; Costello, A.; et al. Health and climate change: Policy responses to protect public health. Lancet 2015, 386, 1861-1914. [CrossRef]

3. Centre for Research on the Epidemiology of Disasters. The Human Cost of Weather Related Disasters (1995-2015); Centre for Research on the Epidemiology of Disasters: Brussels, Belgium, 2015; Available online: https://www.cred.be/index.php?q=HCWRD (accessed on 2 February 2021).

4. Klinenberg, E. Denaturalizing disaster: A social autopsy of the 1995 Chicago heat wave. Theory Soc. 1999, 28, 239-295. [CrossRef]

5. Knowlton, K.; Rotkin-Ellman, M.; King, G.; Margolis, H.G.; Smith, D.; Solomon, G.; Treent, R.; English, P. The 2006 California heat wave: Impacts on hospitalizations and emergency department visits. Environ. Health Perspect. 2008, 117, 61-67. [CrossRef] [PubMed]

6. D'Ippoliti, D.; Michelozzi, P.; Marino, C.; de'Donato, F.; Menne, B.; Katsouyanni, K.; Kirchmayer, U.; Analitis, A.; Medina-Ramón, M.; Perucci, C.A.; et al. The impact of heat waves on mortality in 9 European cities: Results from the EuroHEAT project. Environ. Health 2010, 9, 37. [CrossRef] [PubMed]

7. Robine, J.-M.; Cheung, S.L.K.; Le Roy, S.; Van Oyen, H.; Griffiths, C.; Michel, J.P.; Herrmann, F.R. Death toll exceeded 70,000 in Europe during the summer of 2003. Comptes Rendus Biol. 2008, 331, 171-178. [CrossRef] [PubMed]

8. Schaffer, A.; Muscatello, D.; Broome, R.; Corbett, S.; Smith, W. Emergency department visits, ambulance calls, and mortality associated with an exceptional heat wave in Sydney, Australia, 2011: A time-series analysis. Environ. Health 2012, 11, 3. [CrossRef] [PubMed]

9. Azhar, G.S.; Mavalankar, D.; Nori-Sarma, A.; Rajiva, A.; Dutta, P.; Jaiswal, A.; Sheffield, P.; Knowlton, K.; Hess, J.J.; on behalf of the Ahmedabad HeatClimate Study Group. Heat-related mortality in India: Excess all-cause mortality associated with the 2010 Ahmedabad heat wave. PLoS ONE 2014, 9, e91831. [CrossRef] [PubMed]

10. Eckstein, D.; Künzel, V.; Schäfer, L. Global Climate Risk Index 2018: Who Suffers Most from Extreme Weather Events? WeatherRelated Loss Events in 2016 and 1997 to 2016. Germanwatch Nord-Süd Initiative eV. Available online: https:/ /www.germanwatch. $\mathrm{org} /$ en/node/14987 (accessed on 2 February 2021).

11. Hoag, H. How cities can beat the heat. Nat. News 2015, 524, 402. [CrossRef] [PubMed]

12. Karachi, C. Karachi Heatwave Management Plan: A guide to Planning and Response. Karachi. Available online: http:/ /www. lead.org.pk/attachments/HeatwaveManagementPlan.pdf (accessed on 2 February 2021).

13. Sheikh, M.M.; Manzoor, N.; Adnan, M.; Ashraf, J.; Khan, A.M. Climate Profile and Past Climate Changes in Pakistan; Global Change Impact Studies Center (GCISC)-RR-01: Islamabad, Pakistan, 2009.

14. Chaudhry, Q.Z.; Rasul, G.; Kamal, A.; Ahmad Mangrio, M.; Mahmood, S. Technical Report on Karachi Heat Wave June 2015; Government of Pakistan Ministry of Climate Change, Ministry of Climate Change: Islamabad, Pakistan, 2015.

15. Zhou, L.; Xin, Z.; Bai, L.; Wan, F.; Wang, Y.; Sang, S.; Liu, S.; Zhang, J.; Liu, Q. Perceptions of heat risk to health: A qualitative study of professional bus drivers and their managers in Jinan, China. Int. J. Environ. Res. Public Health 2014, 11, 1520-1535. [CrossRef] 
16. Jonsson, A.; Lundgren, L. Vulnerability and adaptation to heat in cities: Perspectives and perceptions of local adaptation decision-makers in Sweden. Local Environ. 2015, 20, 442-458. [CrossRef]

17. Boeckmann, M.; Rohn, I. Is planned adaptation to heat reducing heat-related mortality and illness? A systematic review. BMC Public Health 2014, 14, 1112. [CrossRef]

18. Wilson, L.; Black, D.A.; Veitch, C. The Heatsafe Preliminary Study: Perceptions of Heat-Wave Events in Australian RESIDENTS aged 75+. Int. J. Aging Soc. 2012, 1, 25-34. [CrossRef]

19. Abrahamson, V.; Wolf, J.; Lorenzoni, I.; Fenn, B.; Kovats, S.; Wilkinson, P.; Adger, W.N.; Raine, R. Perceptions of heatwave risks to health: Interview-based study of older people in London and Norwich, UK. J. Public Health 2008, 31, 119-126. [CrossRef]

20. Bittner, M.-I.; Stößel, U. Perceptions of heatwave risks to health: Results of an qualitative interview study with older people and their carers in Freiburg, Germany. GMS Psycho Soc. Med. 2012, 9. [CrossRef]

21. Lam, M.; Krenz, J.; Palmández, P.; Negrete, M.; Perla, M.; Murphy-Robinson, H.; Spector, J.T. Identification of barriers to the prevention and treatment of heat-related illness in Latino farmworkers using activity-oriented, participatory rural appraisal focus group methods. BMC Public Health 2013, 13, 1004. [CrossRef] [PubMed]

22. Lane, K.; Wheeler, K.; Charles-Guzman, K.; Ahmed, M.; Blum, M.; Gregory, K.; Graber, N.; Clark, N.; Matte, T. Extreme heat awareness and protective behaviors in New York City. J. Urban Health 2014, 91, 403-414. [CrossRef]

23. Jacklitsch, B.L. Assessing Heat-Related Knowledge, Perceptions, and Needs among Emergency Oil Spill Cleanup Responders. University of Cincinnati. Available online: https:/ / etd.ohiolink.edu/apexprod/rws_olink/r/1501/10?p10_etd_subid=156262 \&clear=10 (accessed on 15 February 2020).

24. Varghese, B.M.; Hansen, A.L.; Williams, S.; Bi, P.; Hanson-Easey, S.; Barnett, A.G.; Heyworth, J.S.; Sim, M.R.; Rowett, S.; Pisaniello, D.L. Determinants of heat-related injuries in Australian workplaces: Perceptions of health and safety professionals. Sci. Total Environ. 2020, 718, 137138. [CrossRef] [PubMed]

25. Kajeguka, D.C.; Desrochers, R.E.; Mwangi, R.; Mgabo, M.R.; Alifrangis, M.; Kavishe, R.A.; Mosha, F.W.; Kulkarni, M.A. Knowledge and practice regarding dengue and chikungunya: A cross-sectional study among Healthcare workers and community in Northern Tanzania. Trop. Med. Int. Health 2017, 22, 583-593. [CrossRef] [PubMed]

26. Fusch, P.I.; Ness, L.R. Are we there yet? Data saturation in qualitative research. Qual. Rep. 2015, $20,1408$.

27. Karnieli-Miller, O.; Strier, R.; Pessach, L. Power relations in qualitative research. Qual. Health Res. 2009, 19, 279-289. [CrossRef]

28. Hsieh, H.-F.; Shannon, S.E. Three approaches to qualitative content analysis. Qual. Health Res. 2005, 15, 1277-1288. [CrossRef]

29. Lincoln, Y.S.; Guba, E.G. Establishing trustworthiness. Nat. Inq. 1985, 289, 289-327.

30. Hassan, A.; Mahmood, K.; Bukhsh, H.A. Healthcare system of Pakistan. IJARP 2017, 1, 170-173.

31. Ali, M.; Gilani, D.Q.; ul Abdin, A. Public Health Care and Government Health Expenditures in Pakistan. J. Econ. Impact 2020, 2, 93-98. [CrossRef]

32. Kovats, R.S.; Hajat, S. Heat stress and public health: A critical review. Annu. Rev. Public Health 2008, 29, 41-55. [CrossRef]

33. Ghumman, U.; Horney, J. Characterizing the impact of extreme heat on mortality, Karachi, Pakistan, June 2015. Prehospital Disaster Med. 2016, 31, 263-266. [CrossRef] [PubMed]

34. Maller, C.J.; Strengers, Y. Housing, heat stress and health in a changing climate: Promoting the adaptive capacity of vulnerable households, a suggested way forward. Health Promot. Int. 2011, 26, 492-498. [CrossRef]

35. Guhar, D.; Jamil, N.; Talpur, S.J.; Channa, G.A.; Wajeeh, M.; Khan, M.Z.; Khan, S. The 2016-2017 Chikungunya Outbreak in Karachi. PLoS Curr. 2018, 10. [CrossRef] [PubMed]

36. Tran, K.V.; Azhar, G.S.; Nair, R.; Knowlton, K.; Jaiswal, A.; Sheffield, P.; Mavankar, D.; Hess, J. A cross-sectional, randomized cluster sample survey of household vulnerability to extreme heat among slum dwellers in Ahmedabad, India. Int. J. Environ. Res. Public Health 2013, 10, 2515-2543. [CrossRef] [PubMed]

37. Lundgren-Kownacki, K.; Dahl, M.; Gao, C.; Jakobsson, K.; Linninge, C.; Song, D.; Kuklane, K. Exploring how a traditional diluted yoghurt drink may mitigate heat strain during medium-intensity intermittent work: A multidisciplinary study of occupational heat strain. Ind. Health 2018, 56, 106-121. [CrossRef]

38. Shaikh, B.T.; Hatcher, J. Health seeking behaviour and health service utilization in Pakistan: Challenging the policy makers. J. Public Health 2005, 27, 49-54. [CrossRef]

39. O'Donnell, O. Access to health care in developing countries: Breaking down demand side barriers. Cad. De Saude Publica 2007, 23, 2820-2834. [CrossRef] [PubMed]

40. Dalal, K.; Dawad, S. Non-utilization of public healthcare facilities: Examining the reasons through a national study of women in India. Rural Remote Health 2009, 9, 1.

41. Bouchama, A.; Knochel, J.P. Heat stroke. N. Engl. J. Med. 2002, 346, 1978-1988. [CrossRef] [PubMed]

42. Grubenhoff, J.A.; du Ford, K.; Roosevelt, G.E. Heat-related illness. Clin. Pediatr. Emerg. Med. 2007, 8, 59-64. [CrossRef]

43. Herrmann, A.; Sauerborn, R. General Practitioners' perceptions of heat health impacts on the elderly in the face of climate change-A qualitative study in Baden-Württemberg, Germany. Int. J. Environ. Res. Public Health 2018, 15, 843. [CrossRef]

44. Aziz, S.Z.; Hanif, I. Primary care and health system performance in Pakistan: A study of basic health units of South Punjab. J. Pak. Med. Assoc. 2016, 66, 1632-1636. [PubMed]

45. Shaikh, B.; Rabbani, F.; Safi, N.; Dawar, Z. Contracting of primary health care services in Pakistan: Is up-scaling a pragmatic thinking. J. Pak. Med Assoc. 2010, 60, 387. [PubMed] 
46. Lowe, R.; García-Díez, M.; Ballester, J.; Creswick, J.; Robine, J.M.; Herrmann, F.R.; Rodó, X. Evaluation of an early-warning system for heat wave-related mortality in Europe: Implications for sub-seasonal to seasonal forecasting and climate services. Int. J. Environ. Res. Public Health 2016, 13, 206. [CrossRef]

47. Patton, M.Q. Qualitative research. Encycl. Stat. Behav. Sci. 2005. [CrossRef] 